\title{
Zeolite Nanoclusters Coated onto the Mesopore Walls of SBA-15
}

Do Trong On, Andrei Nossov, Marie-Anne Springuel Huet, Celine Schneider, Jeremy L.

Bretherton, Colin A. Fyfe, and Serge Kaliaguine

\section{Experimental section}

Synthesis: The synthesis of zeolite coated mesoporous materials involves two steps: the first step consists in the preparation of the mesoporous alumosilicate precursor (SBA-15) and of the desired clear zeolite gel. ${ }^{[7]} \mathrm{Clear}$ zeolite gel solutions were prepared with molar composition of 2.5TPAOH : $0.1 \mathrm{Al}_{2} \mathrm{O}_{3}: 10 \mathrm{SiO}_{2}: 250 \mathrm{H}_{2} \mathrm{O}$ for ZSM-5 and $0.15 \mathrm{Na}_{2} \mathrm{O}$ : 5.5 (TMA) $)_{2} \mathrm{O}: 0.5 \mathrm{Al}_{2} \mathrm{O}_{3}: 10 \mathrm{SiO}_{2}: 570 \mathrm{H}_{2} \mathrm{O}$ for faujasite. In a typical ZSM-5 gel synthesis (atomic $\mathrm{Si} / \mathrm{Al}=50$ ), $35 \mathrm{~g}$ of $20 \%$ aqueous solution of TPAOH was added to 19.5 $\mathrm{g}$ of TEOS. To the resulting clear solution, a solution of $0.216 \mathrm{~g}$ sodium aluminate $\left(46.78 \% \mathrm{Al}_{2} \mathrm{O}_{3}, 28.43 \% \mathrm{Na}_{2} \mathrm{O}\right)$ in $25 \mathrm{~g}$ of distilled water was added. The resulting clear solution was stirred for $24 \mathrm{~h}$ at room temperature to form protozeolitic species (known as zeolite seeds) and was finally diluted by distilled water to a volume of $600 \mathrm{ml}$.

In the second step, $20 \mathrm{~g}$ of the calcined mesoporous alumosilicate precursor (SBA-15) was contacted with $600 \mathrm{ml}$ of the diluted ZSM-5 gel prepared above under vigorous stirring at room temperature for $1 \mathrm{~h}$. The solid sample was filtered, washed with distilled water, dried at $80^{\circ} \mathrm{C}$. The resulting solid was subsequently suspended in $50 \mathrm{ml}$ glycerol and the mixture was then transferred into Teflon lined autoclave and heated at $130^{\circ} \mathrm{C}$ for 24 hours. Glycerol was used as the medium for crystallization because due to the low solubility of silica in this medium, the framework was better retained during crystallization. Finally the solid product was filtered, washed with distilled water, dried at $80^{\circ} \mathrm{C}$ and calcined at $550^{\circ} \mathrm{C}$.

Characterization: ${ }^{129} \mathrm{Xe}$ NMR spectra were recorded at $293 \mathrm{~K}$ with a Bruker MSL-300 instrument operating at $83.0 \mathrm{MHz}$. The samples were packed in an NMR tube equipped with a re-sealable valve suited for attachment to a vacuum line, then dehydrated in vacuum at $573 \mathrm{~K}$ for $5 \mathrm{~h}$ before xenon adsorption at room temperature. The samples were equilibrated at different xenon pressures before the NMR tube was sealed. The relaxation delay of $0.5 \mathrm{~s}$ was used to get the spectrum. ${ }^{9}$ The chemical shifts were expressed relative to that of xenon gas extrapolated to zero pressure. ${ }^{27} \mathrm{Al}$ spectra were obtained at 208.43 $\mathrm{MHz}$ (18.8 T, $800 \mathrm{MHz}$ for protons) using home-built MAS probes incorporating a Doty scientific 5mm "SuperSonic" stator assembly on a Varian Inova system at the Pacific Northwest National Laboratory, Richland, Washington. Spinning rates were ca. $15 \mathrm{kHz}$. MAS experiments were conventional and $12^{\circ}$ pulse lengths of $1 \mu$ s were used for the single pulse experiments. Echo experiments used a rotor synchronized " $90^{\circ}-\tau-180^{\circ}-\tau$ acquire" sequence with pulse lengths of $1.7\left(90^{\circ}\right)$ and $3.4 \mu \mathrm{s}\left(180^{\circ}\right)$ and $\tau=0.15,0.30$, $0.60,1.2,2.4 \mathrm{~ms} .{ }^{27} \mathrm{Al}$ MQMAS experiments were run at $195.40 \mathrm{MHz}(17.6 \mathrm{~T}, 750 \mathrm{MHz}$ for protons) with a two-pulse nutation sequence on a Varian Inova system using a similar probe and stator assembly. ${ }^{10}$ 


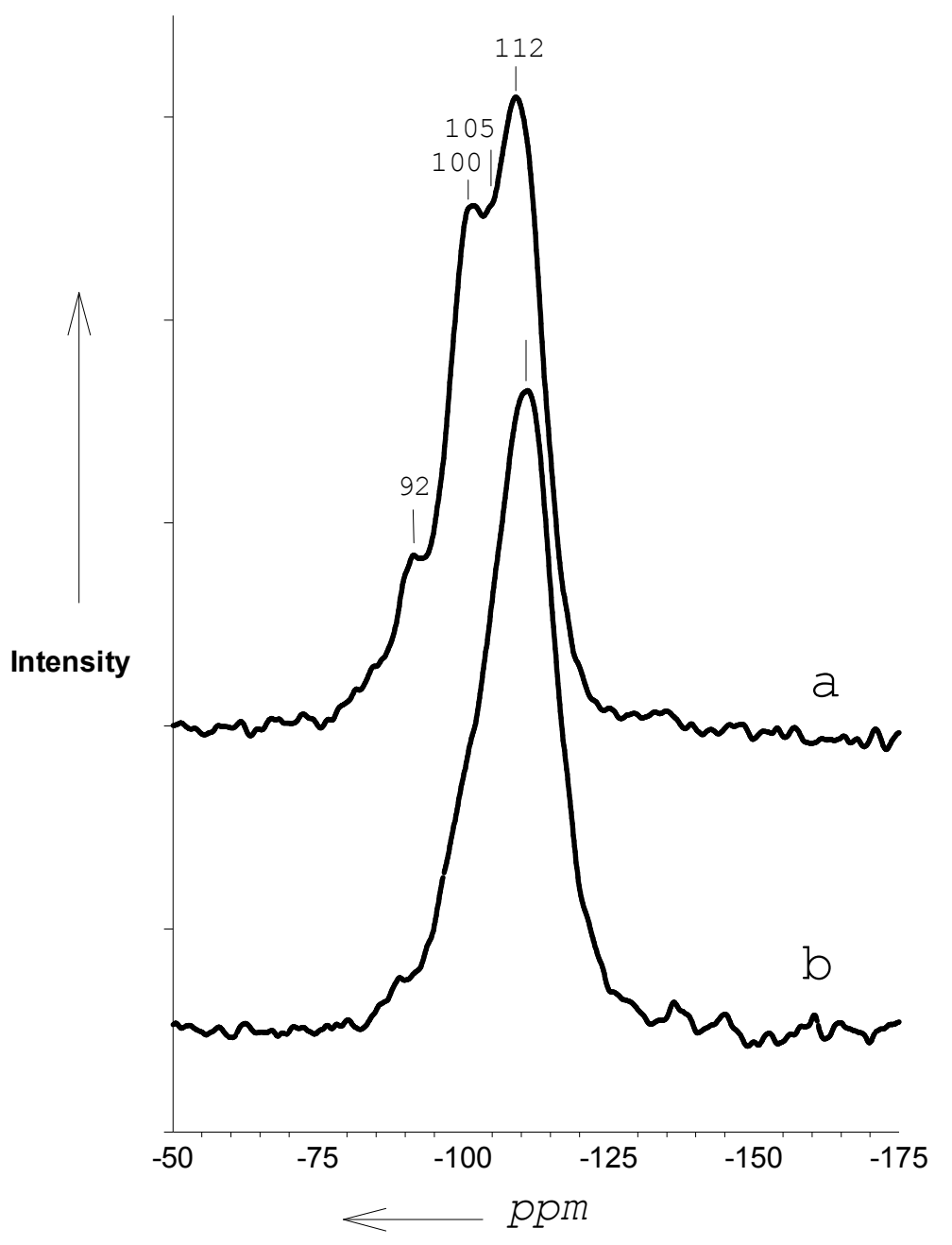

Figure S1: ${ }^{29} \mathrm{Si}$ MAS NMR spectra of: a) parent MesoAS, b) ZSM-5 coated MesoAS at $59.61 \mathrm{MHz}$ 


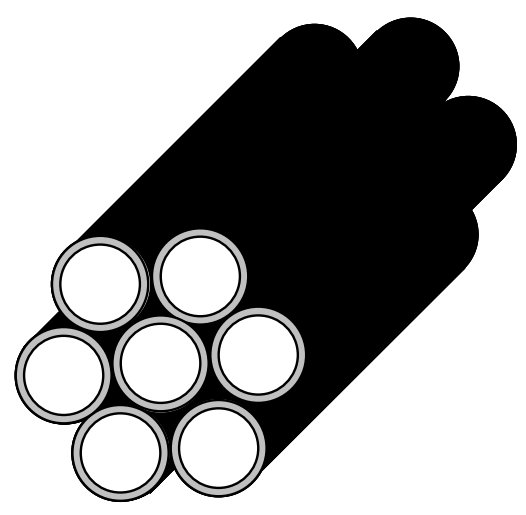

1

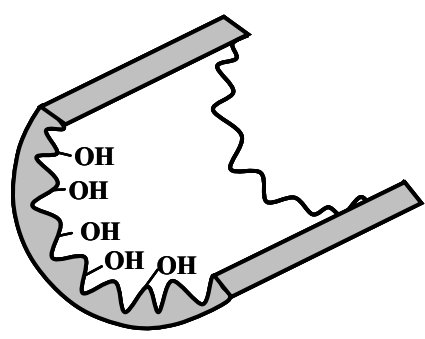

Parent MMS
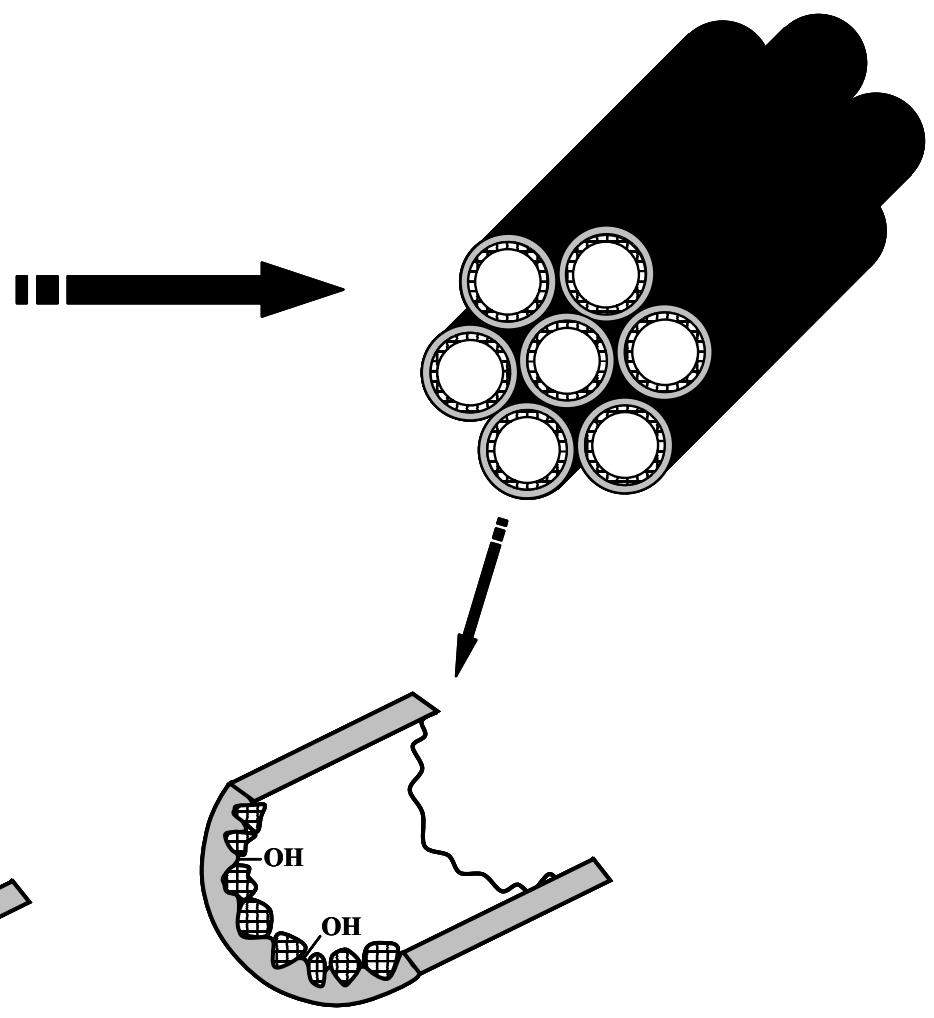

HZSM-5 coated MMS

Figure S2: A schematic presentation of the hexagonal SBA-15 structure before and after nanozeolite seed coating. 